\title{
CARACTERÍSTICAS BIOMÉTRICAS E PARÂMETROS ESPERMÁTICOS DE TESTÍCULOS E EPIDÍDIMOS DIREITOS E ESQUERDOS DE TOUROS ZEBUÍNOS
}

(Biometrics and sperm parameters between right and left testes and epididymis of zebu bulls)

\author{
Melina Andrea Formighieri Bertol, Romildo Romualdo Weiss, Luiz Ernandes Kozicki, Ana \\ Cláudia Machinski Rangel de Abreu \\ *Correspondência: melbertol@hotmail.com:
}

RESUMO: A capacidade reprodutiva de touros é um dos principais fatores que interfere no ganho em produtividade e consequentemente no sucesso da bovinocultura de corte. Os objetivos do estudo foram: comparar os testículos e epidídimos direitos e esquerdos de touros, quanto à dimensão, peso e parâmetros espermáticos, e verificar a correlação entre o peso do testículo e a reserva espermática no epidídimo. Dez touros da raça Tabapuã com idade entre 36 e 84 meses, foram castrados para obtenção e mensuração das estruturas do aparelho sexual externo, e posterior colheita de espermatozoides diretamente da cauda do epidídimo por fluxo retrógrado. O comprimento, largura e altura testicular foram semelhantes $(P>0,05)$. Em relação aos parâmetros espermáticos, os valores médios encontrados para os lados direito e esquerdo foram, respectivamente: motilidade total 63,5 e $62,5 \%$, vigor 4,6 e 4,5 , total de defeitos morfológicos 14,7 e $16,8 \%$ e

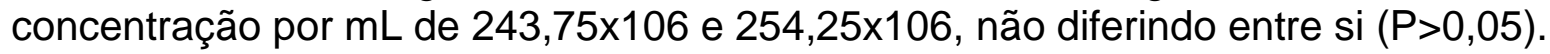
Ocorreu correlação negativa, moderada e não significativa $(r=0,20 ; P>0,05)$ entre a concentração espermática e o peso testicular. Concluímos que ambos os testículos e epidídimos de um bovino possuem dimensões e peso semelhantes e mantêm uma produção de gametas com motilidade, vigor, morfologia e concentração similares.

Palavras-chave: Bos indicus; sêmen; reprodução

\begin{abstract}
The reproductive capacity of bulls is one of the main factors that interfere in productivity gains with the consequent of success in beef cattle. This study aims to compare the differences between rights and left epididymis and testicles of zebu bulls, as the size, the weight and sperm parameters, and also to verify the correlation between the concentration of sperm on epididymis with testicular weight. We use 10 Tabapuã bulls, between 36 and 84 months of age, that were castrated by bilateral orchiectomy with local anesthesia, and after that the sperm were recovery directly from the epididymal tail by retrograde flow. The length, width, height and weight of both testis were similar $(P>0.05)$. Considering the results to sperm parameters, the mean values for the right and left sides were respectively: total motility 63.5 and $62.5 \%$, vigor 4.6 and 4.5 , total morphological defects 14.7 and $16.8 \%$ and concentration per $\mathrm{mL} 243.75 \times 106$ and $254.25 \times 106$, not differing $(P>0.05)$. Negative, moderate and not significant correlation $(r=0.20 ; P>0.05)$ was observe between the concentration of sperm and testicular weight. We concluded that both testes and epididymides of an bull, have similar dimensions and weight and maintain constant production of gametes with similar motility, morphology and concentration.
\end{abstract}

Key Words: Bos indicus; sperm; reproduction 


\section{INTRODUÇÃO}

A pecuária de corte é um dos pilares do agronegócio brasileiro gerando um faturamento de mais de $R \$$ 59 bilhões/ano e oferecendo cerca de 7,5 milhões de empregos (ABIEC, 2010). O Brasil possui o maior rebanho comercial bovino do mundo chegando a 215,2 milhões de cabeças e produz anualmente ao redor de 9,2 milhões de toneladas de carne bovina em área aproximada de 160 milhões de hectares de pastagens (CONAB, 2015).

A capacidade reprodutiva de touros é um dos fatores determinantes para o aumento da produtividade $\mathrm{e}$ consequentemente sucesso da bovinocultura de corte (Santos et al., 2004), visto que a fertilidade do rebanho está diretamente relacionada ao número de fêmeas gestantes (Silva et al., 2002). Segundo Moura et al. (2002) e Salvador et al. (2003), admite-se que o reprodutor possa abranger mais de $90 \%$ do potencial genético de um rebanho, por esse motivo torna-se fundamental o conhecimento da sua capacidade real. Alguns parâmetros como a qualidade do sêmen e as medidas testiculares têm sido propostos para estimar a aptidão reprodutiva do macho, destacando a aferição do perímetro escrotal em função da fácil execução desta medida e por ter alta herdabilidade e repetibilidade e correlação positiva com o peso corporal, idade à puberdade de machos e fêmeas, dentre outras características de interesse econômico (Pereira et al., 2000), e tem sido muito utilizado em programas de melhoramento genético de bovinos (Siqueira et al., 2013).

Caldas et al. (1999) \& Viu et al. (2006) concluíram que, além do perímetro escrotal, o volume, peso e formato testicular podem ser parâmetros úteis na seleção de reprodutores. Somente a circunferência escrotal não constitui medida representativa da produção espermática, sendo que o volume testicular pode ser uma medida complementar para representar esta produção (Bailey et al., 1996; Caldas et al., 1999; Unanian et al., 2000). De acordo com Bailey et al. (1998), os testículos mais longos apresentam maior superfície de contato com o ambiente, o que facilita a termorregulação, além de que a distribuição dos vasos sanguíneos e do tecido espermático é mais uniforme, assim, as formas testiculares mais alongadas seriam mais vantajosas à reprodução. Animais com o mesmo perímetro escrotal, porém com comprimentos testiculares diferentes, apresentam maior volume testicular quanto maior for o comprimento e, portanto, maior produção espermática (Guimarães, 1997). Entende-se que o par de testículos de um reprodutor possua características semelhantes, porém não há na literatura estudos que comparem as dimensões testiculares de um mesmo reprodutor bovino relacionando com a eficiência da produção de gametas e a reserva no epidídimo. A informação torna-se útil, nos casos de comprometimento testicular unilateral, auxiliando no prognóstico reprodutivo do macho e também no auxílio do entendimento da fisiologia normal do aparelho genital masculino.

Os objetivos deste estudo foram comparar as dimensões, o peso e os parâmetros espermáticos (motilidade total, vigor, morfologia espermática e concentração) dos testículos e epidídimos direitos e esquerdos de touros zebuínos, bem como verificar se há correlação entre o peso testicular e a reserva espermática no epidídimo.

\section{MATERIAL E MÉTODOS}

O estudo foi executado em uma fazenda de bovinos de corte e animais de elite situada no sudoeste do estado do Paraná, Brasil (latitude 253'0.4.4"sul, longitude $52^{\circ} 48^{\prime} 58.9^{\prime \prime}$ oeste e altitude de 
Características biométricas e parâmetros espermáticos de testículos e epidídimos direitos e esquerdos de touros zebuínos

$505 \mathrm{~m})$. Dez touros puros de origem da raça Tabapuã (Bos taurus indicus) com idade entre 36 e 84 meses e peso médio de $560 \mathrm{Kg}$ foram selecionados, após exame andrológico completo com resultado satisfatório para a espécie. Uma semana após colheita de sêmen por eletro ejaculação para realização do exame andrológico, os touros foram castrados para obtenção dos testículos e epidídimos, separados em dois grupos, direito e esquerdo, sendo 10 amostras por grupo.

Para a realização da orquiectomia, os animais foram contidos em tronco de contenção, e imobilizados empregando-se uma estrutura metálica arredondada de aproximadamente três metros de comprimento por quinze centímetros de diâmetro, mantida na altura do jarrete e tracionada no sentido caudo-cranial, induzindo a suspensão dos membros pélvicos do animal. A técnica utilizada foi a tradicional descrita por Turner \& Mcllwraith (2002), mediante incisão medial e utilização de anestesia local com lidocaína $2 \%$ sem vasoconstritor. Após o procedimento, os órgãos foram lavados com solução fisiológica previamente aquecida a $37^{\circ} \mathrm{C}$, e dissecados das demais estruturas anexas a eles, o cordão espermático foi seccionado na sua porção proximal ao testículo. Os testículos e epidídimos foram identificados conforme a posição anatômica no animal em direito e esquerdo, e alocados em seus respectivos grupos $(n=10)$.

As duas estruturas (testículos e epidídimos) foram pesadas juntas e em seguida, individualmente em balança digital para determinação do peso em gramas. Para aferição das medidas testiculares (comprimento, largura e altura) utilizou-se fita flexível graduada em centímetros. Os valores foram anotados e somados para obtenção da média aritmética de cada grupo. A mesma pessoa realizou as mensurações de todas as estruturas para minimizar variações que pudessem interferir nos resultados.

$\mathrm{Na}$ sequência, foi realizada a colheita dos espermatozoides diretamente da cauda do epidídimo pela técnica de fluxo retrógrado, adaptada para bovinos. A região da cauda e o ducto deferente foram isolados do corpo e da cabeça do epidídimo com cautela para que ambos permanecessem intactos. Após dissecação precisa do ducto deferente e da porção final do ducto epididimário, a cauda do epidídimo foi perfundida com diluente a base de leite em pó desnatado (Botu-turbo®) aquecido a $37^{\circ} \mathrm{C}$ e com osmolaridade corrigida para a espécie bovina $(20 \mathrm{~mL}$ de água destilada para cada $100 \mathrm{~mL}$ do meio). A solução foi injetada no lúmen do ducto deferente mediante a delicada introdução de uma agulha hipodérmica de $0,7 \mathrm{~mm}$ acoplada a uma seringa de 3 $\mathrm{mL}$. O diluente seguiu o trajeto inverso ao fisiologicamente percorrido pelos espermatozoides e após aplicação de pressão o conteúdo emergiu por um corte feito na junção do corpo com a parte proximal da cauda do epidídimo. 0 procedimento foi repetido até completar o volume fixo de $20 \mathrm{~mL}$ de diluente.

Os espermatozoides diluídos foram depositados em um recipiente aquecido e transferidos para um banhomaria a $29^{\circ} \mathrm{C}$ por uma hora para adaptação e estabilização das células espermáticas e também para 0 desprendimento espontâneo das gotas citoplasmáticas distais. Decorrido esse tempo, uma alíquota de cada amostra foi retirada para avaliação.

A motilidade espermática total foi determinada de forma subjetiva através da observação do percentual (0 a 100\%) de espermatozoides móveis, e o vigor, que representa a força de deslocamento das células foi pontuado numa escala de 0 a 5. Para avaliação, uma gota de amostra (espermatozoides do epidídimo diluídos) de aproximadamente $15 \mu \mathrm{L}$ foi depositada entre lâmina e lamínula 
aquecidas $\left(37^{\circ} \mathrm{C}\right)$ e levada ao microscópio ótico binocular em um aumento de 400 vezes. Para determinação do valor final de motilidade e vigor, cinco campos foram avaliados para obtenção de uma média final de cada amostra do grupo, que posteriormente gerou a média final do grupo.

Para determinação da morfologia dos espermatozoides, foi feito esfregaço delgado em lâmina pré-aquecida a $37^{\circ} \mathrm{C}$ e corada com vermelho congo (Cerovsky, 1976). Após coloração as lâminas foram observadas no microscópio ótico em aumento de 1.000 vezes sob imersão e 200 células foram avaliadas para determinação do percentual total de espermatozoides com defeitos morfológicos. A concentração espermática foi determinada em hemocitômetro à diluição de 1:100 (sêmen: solução de formol-salino tamponado). O resultado foi dado em número de células $/ \mathrm{mL}$ e ao multiplicar o valor pelo volume total da amostra obteve-se 0 número total de espermatozoides.

Para a análise estatística dos dados utilizou-se o teste de Shapiro-Wilk. Para os dados de distribuição não Gaussiana ou para as variáveis categóricas ordinais usou-se o teste de Kruskal-Wallis (motilidade total e vigor), com o pós-teste de Dunn. Para as variáveis contínuas numéricas de distribuição Gaussiana (concentração/mL) empregou-se o teste ANOVA, com o pós-teste de comparações múltiplas de TukeyKramer. Valores de $\mathrm{P}<0,05$ foram considerados significantes. Para execução da estatística descritiva e inferencial usou-se o software StatView (SAS Institute Inc., Cary, NC, EUA)

\section{RESULTADOS E DISCUSSÃO}

Quando comparamos as características biométricas entre testículos e epidídimos direito e esquerdo de bovinos encontramos valores semelhantes $(P>0,05)$, os valores encontrados para o comprimento, largura e o peso estão descritos na Tabela 1. Entende-se que os dois testículos nos bovinos apresentam similaridade de desenvolvimento e morfologia e função fisiológica durante o crescimento do animal, corroborando com Unanian et al. (2000), Pastore et al. (2008) e Machado et al. (2012), que constataram através de análises comparativas que não houve diferença numérica significativa entre as medidas dos testículos direito e esquerdo.

Tabela 1. Características biométricas de testículos e epidídimos direito e esquerdo de touros Tabapuã (Bos taurus indicus).

\begin{tabular}{|lcc|}
\hline & $\begin{array}{c}\text { Direito } \\
(\mathrm{n}=10)\end{array}$ & $\begin{array}{c}\text { Esquerdo } \\
(\mathrm{n}=10)\end{array}$ \\
\hline Peso Total $(\mathrm{g})$ & $311,8 \pm 104,4^{\mathrm{a}}$ & $300,5 \pm 104,1^{\mathrm{a}}$ \\
Peso Testiculo $(\mathrm{g})$ & $275,4 \pm 93,8^{\mathrm{a}}$ & $265,7 \pm 94,8^{\mathrm{a}}$ \\
Peso Epididimo $(\mathrm{g})$ & $34,7 \pm 9,9^{\mathrm{a}}$ & $33,7 \pm 10,08^{\mathrm{a}}$ \\
Comprimento $(\mathrm{cm})$ & $13,2 \pm 1,7^{\mathrm{a}}$ & $12,9 \pm 1,5^{\mathrm{a}}$ \\
Largura $(\mathrm{cm})$ & $6,5 \pm 1,1^{\mathrm{a}}$ & $6,4 \pm 1^{\mathrm{a}}$ \\
Altura $(\mathrm{cm})$ & $4,84 \pm 0,4^{\mathrm{a}}$ & $4,7 \pm 0,5^{\mathrm{a}}$ \\
a= Teste T não pareado com nivel de significância de $0,05 \%$, letras iguais na mesmi \\
linha não diferem entre si. & \\
& & \\
& & \\
& & \\
\end{tabular}

As medidas médias de comprimento e largura testiculares foram semelhantes para os lados direito e esquerdo, assim como os valores encontrados para 0 peso dessas estruturas. Da mesma forma, Silveira et al. (2010), ao analisarem 5.903 touros da raça Nelore, com média de 21 meses de idade, não encontraram diferenças entre as medidas dos lados direitos $e$ esquerdos, sendo detectados nesses animais valores de comprimentos testiculares esquerdo $(11,21 \pm 0,98 \mathrm{~cm})$ e direito $(11,26 \pm 0,97 \mathrm{~cm})$, larguras testiculare esquerda $(5,92 \pm 0,44 \mathrm{~cm})$ e direita $(5,97 \pm 0,46 \mathrm{~cm})$, valores estes próximos aos descritos no presente estudo, com exceção dos valores 
Características biométricas e parâmetros espermáticos de testículos e epidídimos direitos e esquerdos de touros zebuínos

elevados do desvio padrão das médias dos grupos que pode ser explicado pela variação de idade entre os reprodutores que ocasionou diferenças de mais de 100 gramas no peso total entre os indivíduos. Touros com idade mais avançada e tempo mais prolongado em atividade sexual apresentam maior circunferência escrotal com maior quantidade de parênquima testicular, aumentando o peso testicular.

Os valores obtidos para os parâmetros de viabilidade dos espermatozoides recuperados da cauda dos epidídimos direito e esquerdo estão apresentados na Tabela 2. A motilidade total, o vigor, o percentual total de espermatozoides morfologicamente deformados e a concentração (total e por $\mathrm{mL})$ não diferiram $(P>0,05)$ entre direito $e$ esquerdo. Goovaerts et al. (2006), encontraram algumas diferenças entre os lados direito e esquerdo nos parâmetros avaliados em espermatozoides provenientes da cauda do epidídimo de touros de origem européia (Bos taurus taurus).

Tabela 2. Comparação entre parâmetros de viabilidade espermática de espermatozoides colhidos da cauda do epidídimo direito e esquerdo de touros Tabapuã (Bos taurus indicus).

\begin{tabular}{|c|c|c|c|c|c|}
\hline $\begin{array}{l}\text { Lado } \\
(\mathrm{n}=10)\end{array}$ & $\begin{array}{l}\text { MT } \\
(\%)\end{array}$ & Vigor & $\begin{array}{l}\text { EMD } \\
(\%)\end{array}$ & $\begin{array}{l}\text { Concentração } \\
\text { total }\left(10^{6}\right)\end{array}$ & $\begin{array}{c}\text { Concentração.mL } \\
\left(10^{6}\right)\end{array}$ \\
\hline Direito (D) & $63,5^{\mathrm{a}}$ & $4,6^{\mathrm{a}}$ & $14,7^{\mathrm{a}}$ & $4875^{\mathrm{a}}$ & $243,75^{\mathrm{a}}$ \\
\hline $\begin{array}{l}\text { Esquerdo (E) } \\
\text { MT, Motilidade } \\
\text { a = Teste T não } \\
\text { mesma coluna }\end{array}$ & $\begin{array}{l}62,5^{\mathrm{a}} \\
\text { otal; EMD } \\
\text { pareado } \\
\text { âo difere }\end{array}$ & $\begin{array}{c}4,5^{\mathrm{a}} \\
\text { Esperma } \\
\text { om nivel } \\
\text { ie entre si. }\end{array}$ & $\begin{array}{c}16,8^{\mathrm{a}} \\
\text { zzoides m } \\
\text { significâ }\end{array}$ & $\begin{array}{c}5085^{\mathrm{a}} \\
\text { orfologicamente d } \\
\text { ccia de 0,05\%. }\end{array}$ & $\begin{array}{l}254,25^{\mathrm{a}} \\
\text { eformados. } \\
\text { ras iguais na }\end{array}$ \\
\hline
\end{tabular}

As relações entre os parâmetros espermáticos e as características biométricas dos testículos têm sido estudadas por diversos autores. Segundo Dias et al. (2008), as correlações genéticas favoráveis entre circunferência escrotal e características físicas e morfológicas do sêmen são indicação de que a circunferência escrotal é um parâmetro adequado e pode ser usada como critério de seleção em programas de melhoramento visando maiores crescimento corporal e fertilidade. Segundo Pastore et al. (2008), a característica perímetro escrotal apresenta correlação positiva com o volume testicular, a motilidade e o vigor espermático. Godfrey \& Dodson (2005) observaram melhor motilidade e menor incidência de patologias espermáticas com 0 aumento do perímetro escrotal, assim como, Viu et al. (2006) que obtiveram uma correlação negativa entre os defeitos espermáticos com o volume e formato testiculares, além do perímetro escrotal. No presente estudo não foram avaliados o perímetro escrotal e o volume testicular dos touros, nem correlacionados com os parâmetros de viabilidade espermática, uma vez que o objetivo principal foi a comparação entre os lados direito e esquerdo.

Quando considerada a possibilidade de relação entre a concentração de espermatozoides por $\mathrm{mL}$ recuperados da cauda do epidídimo, ou seja, a reserva espermática com o peso dos testículos (parênquima testicular), o que observamos é que não ocorre uma função linear demostrando baixa correlação $(r=0,20)$. A função obtida após plotagem dos dados pode ser descrita pela fórmula: $Y=202,827+$ ,272 * $\mathrm{X}$; R^2= ,207 e não segue uma constante. Isso sugere que outros fatores estão diretamente envolvidos com a quantidade de espermatozoides recuperados da cauda do epidídimo dos touros, entre eles a habilidade do técnico no momento de realização da colheita dos espermatozoides, o método utilizado, a idade do reprodutor, entre outros. Aguiar et al. (2006) mostraram resultados que evidenciam a existência de uma relação cronológica entre os níveis periféricos de gonadotrofinas e esteroides, a espermatogênese e o desenvolvimento testicular em touros 
Angus. Em ovinos, Monteiro (2007) descreveu baixa e moderada correlação das medidas testiculares e epididimárias com a concentração de espermatozoides recuperados do epidídimo nessa espécie, e para Amann \& Schambacker (1983), o peso testicular apresenta alta correlação com a produção de espermatozoides.

Dados das tabelas 1 e 2 indicam que ambos os testículos de um reprodutor da espécie bovina possuem características e funções análogas assim como os outros órgãos pares do organismo.

\section{CONCLUSÃO}

Ambos os testículos e epidídimos (direito e esquerdo) de touros zebuínos da raça Tabapuã possuíram dimensões (comprimento largura e altura) e peso semelhantes. Os parâmetros espermáticos avaliados: motilidade, vigor, morfologia e concentração dos espermatozoides colhidos diretamente da cauda do epidídimo não diferiram $(P>0,05)$ entre lado direito e esquerdo. $E$ foi observado uma baixa correlação entre a concentração dos espermatozoides do epidídimo e o peso testicular em gramas.

\section{AGRADECIMENTOS}

À Coordenação de Aperfeiçoamento de Pessoal de Nível Superior (Capes) e ao Conselho Nacional de Desenvolvimento Científico e Tecnológico (CNPq) pela concessão de bolsa de estudos de Mestrado e Doutorado.

\section{REFERÊNCIAS}

AGUIAR, G.V.; ARAÚJO, A.A.; MOURA, A.A.A. Desenvolvimento testicular, espermatogênese e concentrações hormonais em touros Angus. Revista Brasileira de Zootecnia, v.35, n.4, p.16291638, 2006. Disponível em:
$<$ http://www.scielo.br/scielo.php?script=sci arttext\&pid=S1516-35982006000600008>. Acesso em: 20/02/2015.

AMANN, R.P. \& SCHAMBACKER, B.D. Phisiology of male reproduction. Journal of Animal Science, v.2, p.379-403, 1983.

$\begin{array}{lcc}\text { ASSOCIAÇÃO } & \text { BRASILEIRA } & \text { DE } \\ \text { INDÚSTRIAS } & \text { EXPORTADORAS } & \text { DE }\end{array}$ CARNE - ABIEC. Pecuária brasileira, 2010. Disponível em: <http://www.abiec.com.br/>. Acesso em: 15/02/2013.

BAILEY, T.L.; HUDSON, R.S.; POWE, T.A. et al. Caliper and ultrasonographic measurements of bovine testicles and a mathematical formula for determining testicular volume and weight in vivo. Theriogenology, v.49, n.10, p.581-598, 1998. Disponível em: $<$ http://www.ncbi.nlm.nih.gov/pubmed/10732 037>. Acesso em: 201/02/2015.

BAILEY, T.L.; MONKE, D.; HUDSON, R.S. et al. Testicular shape and its relationship to sperm production in mature Holstein bulls. Theriogenology, v.46, n.3, p.881-887, 1996. Disponível em: <http://www.ncbi.nlm.nih.gov/pubmed/16727 951>. Acesso em: 20/02/2015.

CALDAS, M.E.; PINHO, T.G.; PINTO, P.A. et al. Avaliação da biometria e morfologia testicular de touros jovens da raça Nelore (Bos taurus indicus). Revista Brasileira de Reprodução Animal, v.23, p.210-212, 1999. Disponível em: $<$ http://www.scielo.br/scielo.php?script=sci nlinks\&ref $=000066 \&$ pid $=S 1516$ $3598201200030002000006 \& \mid n g=e n>$. Acesso em: 20/02/2015.

COLÉGIO BRASILEIRO DE REPRODUÇÃO ANIMAL - CBRA. Manual para exame andrológico e avaliação de sêmen animal. 2.ed. Belo Horizonte, 1998. 49p.

COMPANHIA NACIONAL DE ABASTECIMENTO: CONAB. Indicadores da Agropecuária: Quadro de Suprimentos. Disponível em

$<$ http://www.conab.gov.br/conteudos.php?a $=1470 \& \mathrm{t}=2>$. Acesso em: 11/03/2015.

DIAS, J.C.; ANDRADE, V.J.; MARTINS EMERICK, L.L. et al. Correlações genéticas 
Características biométricas e parâmetros espermáticos de testículos e epidídimos direitos e esquerdos de touros zebuínos

e fenotípicas entre características reprodutivas e produtivas de touros da raça Nelore. Pesquisa Agropecuária Brasileira, v.43, n.1, 2008. Disponível em: $<$ http://www.scielo.br/pdf/pab/v43n1/a08v43 n1.pdf>. Acesso em: 18/01/2013.

GODFREY, R.W. \& DODSON, R.E. Breeding soundness evaluations of Senepol bulls in US Virgin Islands. Journal of Animal Science, v.63, 2005. Disponível em: <http://www.ncbi.nlm.nih.gov/pubmed/15629 801 >. Acesso em: 15/02/2013.

GOOVAERTS, I.G.F.; HOFLACK, G.G.; VAN SOOM, A. et al. Evaluation of epididymal semen quality using the Hamilton-Thorne analyzer indicates variation between the two caudae epididymides of same bull. Theriogenology, v.66, n.2, p.323-330, 2006. Disponível em: <http://www.ncbi.nlm.nih.gov/pubmed/16387 353>. Acesso em: 25/03/2015.

GUIMARÃES, J.D. Avaliação andrológica e estudos quantitativos e qualitativos da espermatogênese de touros mestiços $\mathrm{FI}$ Holandês x Zebu e Red Angus x Zebu. Tese (doutorado) - Escola de Veterinária da Universidade Federal de Minas Gerais, Belo Horizonte, 1997.

MACHADO, P.P.; SOUSA, A.L.; REIS, L.F. et al. Modelos matemáticos e correlações de medidas morfométricas testiculares de Bovinos Zebuínos e Azebuados abatidos em São Luís, MA. Revista Brasileira de Reprodução Animal, v.36, n.1, 2012. Disponível em: <http://www.cbra.org.br/pages/publicacoes/r bra/v36n1/pag51-61.pdf. $>$. Acesso em 12/02/2013.

MONTEIRO, A.W.U. Biometria testículo epididimária e reserva espermática de ovinos deslanados sem padrão racial definido. 2007. Fortaleza, 42f. Dissertação (Mestrado em Zootecnia) - Programa de Pós-graduação em Zootecnia, Universidade Federal do Ceará.

MOURA, A.A.A.; RODRIGUES, G.C.; MARTINS FILHO, R. Desenvolvimento ponderal e testicular, concentrações periféricas de testosterona e características de abate em touros da raça Nelore. Revista Brasileira de Zootecnia, v.31, n.2, p.934-943, $2002 . \quad$ Disponível em:
$<$ http://www.scielo.br/scielo.php?pid=S1516 $-35982002000400017 \&$ script=sci_arttext $>$. Acesso em: 25/03/2015.

PASTORE, A.A.; TONIOLLO, G.H.; LÔBO, R.B.; et al. Características biométricas, testiculares, seminais e parâmetros genéticos de touros pertencentes ao programa de melhoramento genético da raça Nelore. Revista Ars Veterinaria, v.24, n.2, $2008 . \quad$ Disponível em: <http://www.arsveterinaria.org.br/index.php/ ars/article/view/183>. Acesso em 12/02/2013.

PEREIRA, E.; ELER, J.P.; FERRAZ, J.B.S. Correlação genética entre perímetro escrotal e algumas características reprodutivas na raça Nelore. Revista Brasileira de Zootecnia, v.29, n.6, p. 1676-1683, 2000. Disponível em:

<http://www.scielo.br/pdf/rbz/v29n6/5695.pd f>. Acesso em: 27/03/2015.

SALVADOR, D.F.; ANDRADE, V.J.; VALE FILHO, V.R. et al. Avaliação da libido de touros Nelore adultos em curral e sua associação com características andrológicas e desempenho reprodutivo a campo. Arquivo Brasileiro de Medicina Veterinária e Zootecnia, v.55, n.5, p.588-593, 2003. Disponível em: <http://www.scielo.br/scielo.php?script=sci arttext\&pid=S0102-09352003000500012>. Acesso em: 25/03/2015.

SANTOS, M.D.; TORRES, C.A.A.; RUAS, J.R.M. et al. Potencial reprodutivo de touros da raça Nelore submetidos a diferentes proporções touro:vaca. Arquivo Brasileiro Medicina Veterinária e Zootecnia, v.56, n.4, $2004 . \quad$ Disponível em:< http://www.scielo.br/pdf/abmvz/v56n4/21987 .pdf>. Acesso em: 20/11/2012.

SILVA, A.E.D.F.; UNANIAN, M.M.; CORDEIRO, C.M.T. et al. Relação da circunferência escrotal e parâmetros da qualidade do sêmen em touros da raça Nelore, PO. Revista Brasileira de Zootecnia, v.31, n.1, p.1157-1165, 2002. Disponível em: <http://www.scielo.br/pdf/rbz/v31n3/13067>. Acesso em: 25/03/2015.

SILVEIRA, T.S.; SIQUEIRA, J.B.; GUIMARÃES, S.E.F. et al. Maturação sexual e parâmetros reprodutivos em touros da raça Nelore criados em sistema extensivo. 
Revista Brasileira de Zootecnia, v.39, n.3, p.503-511, 2010. Disponível em $<$ http://www.scielo.br/scielo.php?script=sci arttext\&pid=S1516-35982010000300008 > . Acesso em: 25/03/2015.

SIQUEIRA, J.B.; GUIMARÃES, J.D.; PINHO, R.O. Relação entre perímetro escrotal e características produtivas e reprodutivas em bovinos de corte: uma revisão. Revista Brasileira de Reprodução Animal, v.37, n.1, p.3-13, 2013. Disponível em: <http://www.cbra.org.br/pages/publicacoes/r bra/v37n1/p3-13\%20\%28RB262\%29.pdf>. Acesso em: 25/03/2015.

TURNER, A.S. \& McIIWRAITH C.W. Técnicas Cirúrgicas em Animais de Grande Porte. São Paulo: Roca, 2002. 341p.

UNANIAN, M.M.; SILVA, A.E.D.F.; McMANUS, $C$. et al. Características biométricas testiculares para avaliação de touros zebuínos da raça Nelore. Revista Brasileira de Zootecnia, v.29, n.1, 2000. Disponível em: $<$ http://www.scielo.br/pdf/rbz/v29n1/5742.pd f>. Acesso em: 20/11/2012.

VIU, M.A.O.; MAGNABOSCO, C.U.; FERRAZ, H.T. et al. Desenvolvimento ponderal, biometria testicular e qualidade seminal de touros Nelore (Bos taurus indicus) criados extensivamente na região centro-oeste do Brasil. Archives of Veterinary Science, v.11, p.53-57, 2006. Disponível em: <http://ojs.c3sl.ufpr.br/ojs/index.php/veterina ry/article/view/7427>. Acesso em: 25/02/2015. 